\title{
PENGARUH METODE LATIHAN SLALOM DRIBLE TERHADAP KETERAMPILAN DRIBBLING SEPAK BOLA MAHASISWA PJKR UNIVERSITAS ISLAM “45” BEKASI
}

\author{
Azi Faiz Ridlo \\ Universitas Islam “45” Bekasi \\ Email : aziewae@gmail.com
}

\begin{abstract}
Abstrak
Tujuan penilitian ini untuk mengetahui apakah metode latihan slalom dribble memberikan pengaruh yang signifikan terhadap keterampilan dribbling mahasiswa PJKR unisma Bekasi. Metode penelitian menggunakan metode penelitian eksperimen. Sedangkan populasi pada penelitian ini adalah mahasiswa pjkr unisma bekasi smester 3. Sampel yang digunakan dalam penelitian ini berjumlah 20 orang, sampel dipilih berdasarkan penggunaan teknik total sample. Prasyarat analisis data yang digunakan adalah uji normalitas dan uji homogenitas. Analisis data yang digunakan dalam penelitian menggunakan uji-t. Dari analisis data, setelah mengikuti metode latihan slalom dribble terjadi peningkatan keterampilan dribbling mahasiswa pjkr unisma bekasi. Hal ini terbukti dari hasil uji-t diperoleh T hitung sebesar 128,5> dibandingkan nilai T tabel 2,09. Artinya metode latihan slalom dribble mempunyai pengaruh yang signifikan terhadap keterampilan dribbling mahasiswa pjkr Unisma bekasi.
\end{abstract}

Kata kunci : latihan, slalom drible, keterampilan dribbling

\begin{abstract}
The purpose of this research is to find out whether the slalom dribble training method has a significant influence on the PJKR students' unilateral dribbling skills in Bekasi. The research method uses experimental research methods. While the population in this study is the student commissioner student training in semester 3. The sample used in this study amounted to 20 people, the sample was chosen based on the use of the total sample technique. The prerequisite for analyzing the data used is the normality test and homogeneity test. Data analysis used in the study used the t-test. From the data analysis, after participating in the slalom dribble training method there was an increase in the dribbling skills of the PKS students in the training center. This is evident from the results of the t-test obtained T count of 128.5 > compared to the value of T table 2.09. This means that the slalom dribble training method has a significant influence on the dribbling skills of the Unisma bekasi students.
\end{abstract}

Keywords: exercise, slalom drible, dribbling skills 


\section{Pendahuluan}

Sepakbola merupakan permainan yang gerakannya kompleks yaitu gabungan dari jalan, lari dan lompat serta unsur kekuatan, kecepatan, ketepatan, kelentukan dan lain-lain. Untuk menjadi seorang pemain sepakbola yang baik, harus menguasai teknik-teknik dasar permainan sepakbola, karena semakin baik seorang pemain dalam mendribel, menembak dan mengoper semakin baik kemungkinan untuk sukses, hal ini harus ditunjang pula kondisi fisik yang baik.

Dalam dunia pendidikan, Sepakbola merupakan salah satu cabang olahraga permainan yang diajarkan di sekolah yang terangkum dalam kurikulum pendidikan jasmani.Upaya meningkatkan keterampilan bermainan sepakbolapara atlet harus menguasai macam-macam teknik dasar bermain sepakbola.Kemampuan atlet menguasai teknik dasar bermain sepakbola dapat mendukung penampilannya dalam bermain sepakbolabaik secara individu maupun secara kolektif.Pentingnya peranan penguasaan teknik dasar bermain sepakbola, maka bagi para pemain pemula harus dilatih secara baik dan benar. Gerakan menembak merupakan salah satu teknik dasar bermain sepakbolayang memiliki konstribusi besar dalam permainan sepakbola.

Daya tarik Sepakbola secara umum sebenarnya bukan lantaran olahraga ini mudah dimainkan. Tetapi, karena Sepakbola lebih banyak menunutut keterampilan pemain di bandingkan olahraga lain. Dengan keterampilan yang dimilikinya, seorang pemain dituntut bermain bagus, mampu menghadapi tekanan-tekanan yang terjadi dalam pertandingan di atas lapangan dengan waktu yang terbatas, kelelahan fisik dan lawan tanding yang tangguh. Pengetahuan tentang taktik dan strategi sangat penting.Kesigapan pemain dalam mengambil keputusan harusnya diuji terus-menerus karena pemain dituntut memiliki kepekaan yang tinggi terhadap perubahanperubahan situasi yang amat sering terjadi sepanjang permainan. Meskipun dalam permainan sepakbola tidak ditentukan berat atau ukuran pemain secara khusus, semua pemain harus memiliki tingkat kebugaran yang tinggi dilapangan, pemain dituntut berlari terus-menerus selama pertandingan berlangsung. Tantangan fisik dan mental yang dihadapi pemain benar-benar luar biasa. Keberhasilan tim dan individu dalam bermain pada akhirnya bergantung sepenuhnya pada kemampuan pemain dalam menghadapi tantangan-tantangan yang ada.Kemampuan demikian tentunya sangat perlu dikembangkan. Mereka pemain sepakbola ini bukan tidak mungkin karena bakat atau latihanlatihan keras dan serius dalam berbagai aspek. Salah satunya adalah latihan dribbling yang nantinya sangat membantu mereka mempunyai kemampuan akan melakukan mencetak angka.

Agar dapat menembak dengan baik dan berhasil seorang pemain sepakbola hendaklah melakukan dengan teknik dan posisi yang tepat. Dengan semakin meluasnya perkembangan dunia olahraga, maka semakin komplek pula faktor - faktor penunjang untuk mencapai tingkat prestasi yang tinggi 
dan cabang olahraga tertentu, terutama cabang olahragasepakbola. Untuk mencapai prestasi dalam setiap cabang olahraga, tentu mempunyai standarstandar kriteria latihan-latihan terhadap cabang olahraga yang ditekuni, sehingga di dalam pembinaan dan pengembangan atlet nantinya tidak menimbulkan perasaan bosan dan jenuh terhadap program latihan yang diberikan terhadap atlet itu sendiri. Dari uraian dan penjelasan tersebut, maka dalam halini penulis mengemukakan bahwa latihan dribbling tidak boleh disampingkan, tetapi harus menjadi perhatian dalam membina atlit atau murid untuk mencapai prestasi yang lebih baik terutama dalam cabang olahraga sepakbola sebab apabila hal ini dibiarkan maka prestasi atlit atau murid bisa menjadi turun. Mengingat pentingnya unsur keterampilan dalam pemain Sepakbola khususnya dalam dribbling, maka perlu diteliti tentang latihan dribbling.

Pada umumnya mahasiswa pjkr unisma bekasi mempunyai berbagai karakter individu permainan dan teknik perorangan. Dalam halini peneliti melihat mahasiswa pjkr unisma bekasi mempunyai banyak pemain/player yang berposisi pemain serang kusunya pemain winger yang harus ditutut keterampilan menggiring bola yang sangat baik. Maka peneliti tertarik melakukan penelitian tentang dribbling dari maslah yang ada didalam perkuliahan sepak bola mahasiswa pjkr unisma bekasi, maka peneliti tertarik untuk meneliti tentang pengaruh latihan slalom dribble terhadap kemampuan dribbling sepakbola mahasiswa pjkr unisma bekasi.
Berdasarkan permasalahan di atas maka dapat di simpilakan bahwa perlu adanya untuk menganalisis lebih jauh mengenai minat minat mahasiswa pjkr unisma bekasi. Maka dari itu tujuan penelitian ini adalah untuk mengetahui seberapa besar pengaruh latihan slalom dribble terhadap keterampilan dlibbling mahasiswa pjkr unisma bekasi.

\section{Prinsip Latihan}

Prinsip latihan menurut Apta mylsidayu (2014: 88) merupakan halhal yang harus ditaati,dilakukan atau dihindari agar tujuan latihan dapat tercapai sesuai dengan yang diharapkan. Prinsip latihan memiliki peran penting terhadap aspek fisiologis olahragawan. Dengan memehami prinsip-prinsip latihan, akan mendukung upaya dalam meningkatkan kualitas latihan. Selain itu, akan dapat menghindarkan olahragawan dari rasa sakit dan timbulnya cidera selama dalam proses latihan. Dalam setiap kali tatap muka seluruh prinsip latihan dapat diterapkan secara bersama dan saling mendukung. Apabila ada prinsip latihan yang tidak diterapkan, maka akan berpengaruh terhadap keadaan fisik dan pisikis olahragawan. Untuk itu, para pelatih perlu memahami beberapa prinsip latihan tersebut dan dapat menerapkannya dalam proses latihan.

Dalam mempelajari dan menerapkan prinsip-prinsip latihan ini harus hati-hati,serta memerlukan keteitian, ketepatan dalam penyusunan dan pelaksanaan program. Pada dasarnya latihan olahraga adalah merusak,tetapi proses perusakan yang dilakukan agar berubah menjadi lebih baik, tetapi dengan syarat pelaksanaan 
latihan harus mengacu dan berpedoman pada prinsip-prinsip latihan. Proses latihan yang menyimpang dari prinsip latihan sering kali mengakibatkan kerugian bagi olahragawan maupun pelatih.

\section{Keterampilan Dribbling}

Menurut Danny Mileke (2007:01) Kemampuan untuk melakukan dribbling menggunakan kaki. Kebanyakan dari kita telah mengenal istilah dribbling dan sering mengaitkannya dengan permainan bola basket. Dribbling dalam sepakbola didefinisikan sebagai penguasaan dengan kaki saat begerak di lapangan permainan.

Dribbling adalah keterampilan dasar dalam sepakbola karna semuah pemain harus mampu menguasai bola saat sedang bergerak, berdiri,atau bersiap melakukan operan atau tembakan. Ketika pemaintelah menguasai kemampuan dribbling secara efektif, sumbangan mereka di dalam lapangan akan sangat besar. Pada kebanyakan kasus, pemain pemula akan memilih melakukan dribbling dengan menggunakan sisi bagian dalam saja. Ketika kamu semakin matang sebagai pemain dan merasa percaya diri terhadap kemampuan dribbling, cobalah mengontrol bola menggunakan sisi kura-kura kaki dan sisi kaki bagian luar.

\section{Latihan slalom}

Latihan dribble slalom menurut pendapat Mielke (2003: 8) adalah "suatu bentuk latihan dribble dengan gaya zig-zag melewati rintangan”. Pada penelitian ini,penulis menggunakan bentuk latihan dribble slalom untuk mengembangkan keterampilan dribbling bola. Selama program latihan dribble slalom berlangsung, pemain diajarkan merapakan komponen teknik dribbling bola melewati rintangan. Bentuk latihan dribble slalom inipun mempunyai kelebihan dan kekurangannya sebagai berikut:

Kelebihan latihan dribble slalom. Mengacu pada pengertian dan cara pelaksanaannya, bahwa latihan dribble slalom mempelajari keterampilan dribbling bola dengan cara melewati rintangan saja. Bentuk latihan dribble slalom diajarkan terus-menerus setiap kali latihan atau pertemuan,sehingga dalam latihan ini pengulangan dribbling bola lebih banyak, maka penguasaan keterampilan dribbling bola akan meningkat secara optimal.

Kekurangan latihan dribble slalom adalah latihan yang dilakukan akan menimbulkan kebosanan, karna hanya melakukan latihan dribling bola dengan cara melewati rintangan saja. Kegiatan latihan yang monoton akan menimbulkan ketidakpuasan atlit mengikuti latihan.

\section{BAHAN DAN METODE/METODOLOGI}

Metode penelitian yang di gunakan dalam penelitian ini adalah metode eksperimen dengan menggunakan rancangan pretest-postes dengan total sampling 20 orang. Instrument yang digunakan dalam penelitian ini adalah tes keterampilan sepak bola (tes menggiring bola/dribbling), yang dikutip dari "Modul Tes dan Pengukuran Olahraga”,Drs.H. Nurhasan M,PD. Dan Drs. D. Hasanudin Cholil (2007 : 211).

Adapun penjelasan tentang tes menggiring/dribbling bola adalah 
sebagai berikut, Tujuan : Mengukur keterampilan, kelincahan,dan kecepatan kaki dalam memainkan bola. Alat yang digunakan: Bola ,Stop watch, 6 buah rintangan (tongkat/lembing), Tiang bendera, Petunjuk pelaksanan tes : 1). Pada aba aba "siap" testee berdiri di belakang garis star dengan bola dalam penguasaan bola dalam pengiuasan kakinya. 2). Pada aba aba “ya”,tesee mulai menggiring bola ke arah kiri melewati rintangan pertama dan berikutnya menuju rintangan berikuitnya sesuai dengan arah panah yang telah di tetapkan sampai ia melewati garis finish. 3). Salah arah dalam menggiring bola,ia harus memeperbaikinya tanpa menggunakan anggota badan selain kaki dimana melakukan kesalahan dan selama itu pula stop watch tetap jalan. 4). Menggiring bola dilakukan oleh kaki kanan dan kiri bergantian,atau minimal salah satu kaki pernah menyentuh bola satu kali sentuhan.

\section{Hasil dan Pembahasan}

Setelah dialakukan peneilitian dimana data tersebut telah dianalisa sesuai dengan tahapan yang telah dijelaskan. Analisa awal yaitu mencari rata-rata dan simpangan baku dari perhitungan data-data tersebut maka didapat jumlah rata-rata dan simpangan baku, hasil dari rekapitulasi perhitungan data dapat dilihat pada table berikut :

Hasil perhitungan Mean dan simpangan baku dari hasil tes

\begin{tabular}{llllc}
\hline Instrument & $\sum \mathrm{x}$ & Mean & $\mathrm{S}$ & $S^{2}$ \\
\hline Tes awal & 459.99 & 22.99 & 2.34 & 5.46 \\
\hline Tes akhir & 408.47 & 20.42 & 2.43 & 5.89 \\
\hline peningkatan & 51.52 & 2.58 & 1.75 & 3.06
\end{tabular}

Dari hasil data nilai rata-rata dan

nilai simpangan baku diatas maka selanjutnya uji statistic diantaranya, yaitu :

\section{Uji Normalitas}

Menguji normalitas dengan uji lilifors menguji normalitas dilakukan untuk mengetahui apakah sample tersebut berasl dari populasi berdistribusi normal sesuai dengan tahap penguasaaan yang telah dilakukan.

Rekapitulasi uji normalitas

\begin{tabular}{llll}
\hline Instrument & $L_{o}$ hitung & $\begin{array}{l}L_{o} \\
\text { tabel }\end{array}$ & Ket \\
\hline Tes awal & 0.1246 & 0.190 & Normal \\
\hline Tes akhir & 0.1446 & 0.190 & Normal \\
\hline Peningkatan & 0.1551 & 0.190 & Normal \\
\hline
\end{tabular}

Dari table diatas hasil dari tes awal didapat $L_{o}=0.1246$ sedangkan dari daftar table uji lilifors dengan $\mathrm{n}=$ 20 dan taraf nyata $\alpha=0.05$ diperoleh $\mathrm{L}$ $=0.190$. bila dibandingkan dengan nilai $L_{o}=0.1246$ dengan nilai $L$ table, maka nilai $L_{o}=0.1246$ lebih dari $\mathrm{L}=0.190$ sehingga hipotesis nol diterima. Kesimpulannya data berdistribusi normal.

Dari table diatas hasil dari tes akhir didapat $L_{o}=0.1446$ sedangkan dari daftar table uji lilifors dengan $\mathrm{n}=$ 20 dan taraf nyata $\alpha=0.05$ diperoleh $\mathrm{L}$ $=0.190$. bila dibandingkan dengan nilai $L_{o}=0.1446$ dengan nilai $L$ table maka nilai $L_{o}=0.1446$ lebih kecil dari $\mathrm{L}=$ 0.190 sehingga hipotesis nol diterima. Kesimpulannya data berdistribusi normal.

Table diatas hasil dari peningkatan didapat $L_{o}=0.1551$ sedangkan dari daftar table uji lilifors dengan $\mathrm{n}=20$ dan taraf nyata $\alpha=0.05$ diperoleh $\mathrm{L}=0.190$. bila dibandingkan dengan nilai $L_{o}=0.1551$ dengan nilai $\mathrm{L}$ table maka nilai $L_{o}=0.1551$ lebih kecil 
dari $\mathrm{L}=0.190$ sehingga hipotesis nol diterima. Kesimpulannya data berdistribusi normal.

\section{Uji homogenitas}

Untuk batas kritis daerah penolakan dan daerah penerimaan perlu diadakan uji homogenitas dengan cara membagi nilai variasi terbesar dengan membagi nilai variasi terkecil untuk hasil tes awal dan tes akhir, dan hasil perhitungan tersebut dan selanjutnya nilai $\mathrm{F}$ yang dapat dibandngkan dengan nilai $\mathrm{F}$ terdapat pada table.

\begin{tabular}{llll}
\multicolumn{4}{c}{ Rekapitulasi uji homogenitas } \\
\hline Subjek & F hitung & $\begin{array}{l}\text { F } \\
\text { table }\end{array}$ & Ket \\
\hline $\begin{array}{l}\text { Tes } \\
\text { awal }\end{array}$ & 1.079565 & 3,00 & Homogen \\
Tes & & & \\
akhir & & & \\
& & &
\end{tabular}

Batas kritis penolakan dan penerimaan hipotesisnya adalah $\mathrm{dk}$ pembilang $\left(n_{1}-1\right)=(20-1)=19$ dan dk penyebut $\left(n_{2}-1\right)=(20-1)-19$ dengan taraf nyata $(\alpha)=0.05$ dari daftar distribusi $\mathrm{F}$ diperoleh nilai $\mathrm{F}$ table $=$ 3,00 Karena nilai $F_{\text {hitung }}=1.079565<$ nilai $F_{\text {tabel }}=3,00$ Maka hipotesis diterima sehingga kesimpulannya adalah hasil data tes awal dan tes akhir dikatakan mempunyai variansi yang besar (homogen).

\section{Pengujian hipotesis}

Uji perkembangan latihan dengan menggunkan uji untuk melihat hasil perkembangan darihasil tes awal dan tes akhir serta tes peningkatan.Hasil perkembangan dengan uji t dari sample, dapat dilihat dari table di atas.

Hasil penghitungan dan uji hipotesis

\begin{tabular}{lllll}
\hline Subyek & $\begin{array}{l}\mathrm{T} \\
\text { hitung }\end{array}$ & $\begin{array}{l}\mathrm{T} \\
\text { table }\end{array}$ & Hipotesa & Ket \\
\hline Peningkatan & 128,5 & 2,09 & 0,975 & Signifikan
\end{tabular}

Dari hasil perhitungan diperoleh nilai t hitung $=128,5$ bila dibandingkan dengan batas kritis penerimaan dan penolakan hipotesis pada $\mathrm{dk}=\left(n_{1}-1\right)$ $=(20-1)=19$ dengan taraf $(\alpha)=0.05$ diperoleh oleh angka t $(0,975: 19)=$ 2,09 Sehingga nilai $\mathrm{t}$ hitung $=128,5>\mathrm{t}$ table $=2,09$. kesimpulan adalah hipotesis ditolak dengan kata lain ada peningkatan signifikan dari hasil latihan menggunakan metode latihan slalom dribble terhadap keterampilan dribbling mahasiswa pjkr unisma bekasi.

\section{PEMBAHASAN}

Dribbling merupakan cara membawa atau menggiring bola dari satu tempat ke tempat lain dengan menggunakan kaki bagian dalam sbagai pengontrol . dalam permainan sepakbola, dribbling menggunakan kaki bagian dalam dan luar, namun menggunakan punggung kaki juga sering digunakan dalam menggiring bola.

Dalam permainan sepakbola dribbling merupakan keterampilan penting dan mutlak yang harus dikuasai oleh setiap pemain. Seorang pemain sepakbola dalam melakukan dribble harus menguasai bola serta menjaga jarak dengan lawan, dan menjaga keseimbangan badan pada saat melakukan dribbling, serta memfokuskan pandangan setiap kali sentuhan dengan bola.

Untuk bisa melakukan teknik dribbling dengan baik setiap pemain membutuhkan dribble yang bagus diantaranya adalah keterampilandan kelincahan yang baik saat melakukan dribbling akan membuat lawan sangat sulit untuk mengejar pemain tersebut. 
Hasil penelitian ini menunjukan bahwa hipotesis ditolak $H_{o}$ diterima, artinya variable $\mathrm{X}$ berpengaruh terhadap variable $\mathrm{Y}$ dalam arti terbapat pengaruh latihan menggunakan metode latihan slalom dribble terhadap keterampilan dribbling sepak bola mahasiswa pjkr unisma bekasi.

Melihat pengaruh secara parsial masing-masing dribble memberikan pengaruh yang cukup besar, sedangkan pengaruh secara bersama-sama keterampilan dribbling hanya 2,576\% yang mempengaruhi hasil dribbling.

\section{KESIMPULAN SIMPULAN}

Berdasarkan hasil penilitian, kemudian data diolah kedalam perhitungan statistik yang selanjutnya dianalisis. Maka peneliti menyimpulkan kesimpulan sebagai berikut.

Dari hasil tes awal dribble sepakbola sebelum diberikan latihan, yang kemudian sample diberikan latihan dengan dribble slalom menunjukan perbedaan yang berarti. Hasilnya sampel mengalami penurunan dari waktu terbaik. Hipotesis yang dianjurkan peneliti diterima, bahwa latihan dribble slalom berpengaruh terhadap keterampilan dribbling sepakbola mahasiswa.

Kecepatan dribbling sepakbola sebelum diberikan latihan dengan dribble slalom rata-rata 22,9995 setelah sample diberikan latihan dengan dribble slalom 14 kali pertemuan, yang selanjutnya melakukan tes akhir. Dari hasil tes akhir didapat rata-rata 20,4235 mengalami penurunan yang signifikan.

\section{DAFTAR PUSTAKA}

Arikunto, S. (2006). Prosedur Penelitian Suatu Praktek. Jakarta: Rineka Cipta.

Fleck, T dan Quinn, R. (2002). Panduan Latihan Sepak Bola Andal. USA: Ragged Mountain Press.

Giriwijoyo, (2007). Ilmu Faal Olahraga. Bandung: FPOK UPI Bandung.

Harsono. (1998). Coaching Dan Aspekaspek Psikologis Dalam Coaching. Jakarta: C.V Tambak Kusuma.

Imanudin, I. (2008). Ilmu Kepelatihan Olahraga. Bandung: FPOK UPI.

Kosasih, E. (1985). Olahraga Teknik \& Program Latihan. Jakarta : Akademika Pressindo.

Lingling dkk, (2009). Model Pelatiha Cabang Olahraga Sepakbola. Bandung:FPOK UPI Bandung.

Mahendra, A. (2007). Teori Belajar Mengajar Motorik. Bandung: FPOK UPI.

Nurhasan dan Cholil, D.H. (2007). Tes dan Pengukuran Pendidikan Olahraga.Bandung: FPOK UPI 